\title{
Um estudo dos resultados da Prova Brasil na disciplina de Matemática no estado do Rio de Janeiro
}

\section{Elisângela de Souza}

Secretaria Municipal de Educação de Macaé

Faculdade Professor Miguel Ângelo da Silva Santos (FeMASS)

lisdapaz@hotmail.com

\section{Resumo}

As avaliações de larga escala surgiram diante da necessidade de avaliação da educação básica brasileira. A Prova Brasil, avaliação integrante do SAEB, é aplicada desde 2005 e busca fazer um diagnóstico do ensino do país. O presente trabalho tem como objetivo fazer uma análise descritiva dos dados referentes a média de proficiência em Matemática nas duas últimas edições da Prova Brasil (2013 e 2015) no estado do Rio de Janeiro, que são disponibilizados pelo Instituto Nacional de Pesquisas Educacionais (INEP). O estudo observou algumas variáveis relacionadas à escola para verificar se existe possível relação com a média alcançada na disciplina de Matemática. Constatouse que existe uma variação entre as diferentes localidades do estado do Rio de Janeiro, e que as médias ainda demonstram o baixo desempenho na disciplina, pois o resultado da maioria dos municípios foi aquém do necessário.

Palavras-chave: Prova Brasil. Matemática. Avaliação do ensino.

\section{A study of the results of the Prova Brasil in Mathematics in the state of Rio de Janeiro}

\begin{abstract}
Large-scale evaluations arose in view of the need to evaluate Brazilian basic education. Prova Brasil, an integral evaluation of SAEB, it has been applied since 2005 and seeks to make a diagnosis of the country's education. The present work has as objective to make a descriptive analysis of the data concerning the average of mathematics proficiency of the last two editions of the Prova Brasil (2013 and 2015) in the state of Rio de Janeiro, which are made available by the National Institute of Educational Research (INEP). The study observed some variables related to the school to verify if there is possible relation with the achieved average in the Mathematics discipline. It was verified that exist a variation between the different localities of the state of Rio de Janeiro, and that the averages still show the low performance in the discipline, since the result of the majority of the municipalities was less than necessary.
\end{abstract}

Keywords: Prova Brasil. Mathematics. Teaching evaluation. 


\section{Introdução}

As avaliações de larga escala estão presentes na educação brasileira visando avaliar o ensino público e privado no país. Estas avaliações têm expandido nas diversas esferas públicas do Brasil e oferecem informações para diagnósticos, análises e medidas governamentais.

A implementação da avaliação de larga escala no Brasil é recente. Becker (2010) destaca que o Sistema Nacional de Avaliação da Educação Básica (SAEB), implantado no ano 1990, foi a primeira iniciativa no país, existindo até os dias atuais. O sistema é coordenado pelo Instituto Nacional de Estudos e Pesquisas Educacionais Anísio Teixeira (INEP).

Este trabalho objetiva realizar uma análise descritiva com os resultados obtidos na proficiência de Matemática na Prova Brasil no estado do Rio de Janeiro de 2015, edição mais recente até então, relacionando-os com algumas variáveis referentes à escola.

\section{O SAEB e a Prova Brasil}

A Prova Brasil é parte integrante do Sistema Nacional de Avaliação da Educação Básica (SAEB) e avalia a proficiência dos estudantes do $5^{\circ}$ e $9^{\circ}$ anos do ensino fundamental público, nas disciplinas de Língua Portuguesa e Matemática, das escolas com mais de 20 alunos matriculados em cada série/ano de escolaridade pesquisado. Além da Prova Brasil, o SAEB é composto pela Avaliação Nacional da Alfabetização (ANA), uma avaliação censitária abrangendo os alunos do $3^{\circ}$ ano do ensino fundamental das escolas públicas e pela Avaliação Nacional da Educação Básica (ANEB), que é realizada de maneira amostral, contemplando alunos das redes públicas e privadas do país, em áreas urbanas e rurais, matriculados na $4^{\mathrm{a}}$ série $/ 5^{\circ}$ ano e $8^{\mathrm{a}}$ série $/ 9^{\circ}$ ano do ensino fundamental e no $3^{\circ}$ ano do ensino médio (INEP, 2016b).

O SAEB começou a ser aplicado em 1990, sendo ofertado a uma amostra de escolas que ofertavam as $1^{\mathrm{a}}, 3^{\mathrm{a}}, 5^{\mathrm{a}}$ e $7^{\mathrm{a}}$ séries do ensino fundamental das escolas públicas da rede urbana nas disciplinas de Língua Portuguesa, Matemática e Ciências, em que, nas duas últimas séries citadas, os alunos também foram avaliados em Redação. No ano 1995 foi instituída a Teoria de Resposta ao Item (TRI), permitindo a comparabilidade entre os resultados das avaliações longitudinais. Nas edições seguintes, o SAEB passou por algumas adaptações e, em 2005, o sistema foi dividido em duas avaliações: Avaliação Nacional da Educação Básica (Aneb) e Avaliação Nacional do Rendimento Escolar (Anresc), conhecida como Prova Brasil. No ano de 2013 a ANA passou a compor o SAEB juntamente com as outras avaliações (INEP, 2016b).

A Prova Brasil é aplicada a cada dois anos e tem como objetivo principal investigar a qualidade do ensino ministrado nas escolas das redes públicas de ensino, disponibilizando os resultados tanto para as redes de ensino, quanto para cada unidade escolar. Esta avaliação busca 
também produzir informações que visam subsidiar a formulação, reformulação e o monitoramento das políticas públicas educacionais (INEP, 2016b).

Os resultados obtidos na Prova Brasil servem como base para o Índice de Desenvolvimento da Educação Básica (IDEB), composto em 2007 como o objetivo de mensurar a qualidade tanto por escola, quanto por município. O IDEB tem como uma das funções orientar o planejamento das políticas de educação, porque as escolas de menor rendimento recebem auxílio por meio do Plano de Desenvolvimento da Escola (PDE) prioritariamente e ainda são geradas metas para os anos seguintes (BRASIL, 2016).

Na Prova Brasil são avaliadas habilidades e competências definidas em unidades chamadas descritores, reunidas em tópicos formando a Matriz de Referência de cada disciplina (INEP,2016a). Em Matemática, destacam-se quatro blocos de conteúdos: Números e Operações, Espaço e Forma, Grandezas e Medidas e Tratamento da Informação. Para a disciplina de Matemática, o resultado é divulgado numa escala de 125 a 375 para o $5^{\circ}$ ano do ensino fundamental, de 200 a 425 para o $9^{\circ}$ ano do ensino fundamental e de 225 a 475 para o ensino médio, sendo esta pontuação separada em níveis (INEP, 2016 a).

Becker (2010) destacou que o SAEB viabilizou identificar os problemas do ensino e suas diferenciações regionais através de dados e indicadores, que permitiram uma melhor compreensão dos fatores que influenciam o desempenho dos alunos. Para a autora, este sistema ainda possibilitou que, tanto a sociedade em geral como os agentes educacionais pudessem ter uma percepção real dos resultados dos processos de ensino e aprendizagem e das circunstâncias em que são desenvolvidos.

\section{Fatores que podem influenciar no desempenho dos estudantes}

Segundo UNICEF, PNUD, INEP-MEC (2004), os indicadores de qualidade na educação são: ambiente educativo, prática pedagógica, avaliação, gestão escolar democrática, formação e condições de trabalho dos profissionais da escola, espaço físico escolar e acesso, permanência e sucesso na escola. Estes foram formados para auxiliar a comunidade escolar na avaliação e na melhoria da qualidade da escola. Além destes fatores que influenciam num bom desempenho escolar dos estudantes, estudos como de Menezes Filho (2007) apontaram que as variáveis do aluno e de seus familiares são as que tem maior influência e poder explicativo para a proficiência e com maior destaque está a escolaridade da mãe. Barros et al (2001) justificaram que pais com maiores escolaridades possuem maiores recursos para ajudarem na educação de seus filhos, e ainda destacam que escolaridade destes está relacionada com a renda.

[...]a escolaridade dos pais não apenas eleva a renda familiar de forma permanente, mas, também, pode ser um importante fator na redução do custo da educação para os filhos e, portanto, aumentar sua demanda por escolaridade. De fato, como o 
apoio dos pais é sempre um insumo de grande importância na produção da escolaridade, quanto mais elevada a escolaridade dos pais, menores tendem a ser as dificuldades e os custos de aprendizagem dos filhos 16 e, portanto, maior sua escolaridade. (BARROS et al., 2001, p. 10)

Valle Silva e Barbosa (2012) enfatizaram que, além da origem social, aparece como um fator importante para o desempenho educacional, o desempenho individual do aluno e a qualidade da escola. Os autores ressaltaram que "a escola não foi capaz ainda de reduzir substancialmente os impactos da origem social dos alunos sobre o seu destino, permanecendo a instituição reprodutora dos piores cenários.” (VALLE SILVA; BARBOSA, 2012, p. 178).

O trabalho de Alves e Soares (2013) analisou os dados do IDEB de 2009 e concluiu que o maior impacto neste índice é a composição do grupo de alunos matriculados no estabelecimento de ensino. Os autores consideraram que, nas instituições escolares que agregam uma quantidade maior de estudantes com condições socioeconômicas desfavoráveis, é muito mais difícil alcançar as metas associadas ao IDEB. Alves e Soares (2013, p. 190) afirmaram que "esse fator só mudará na medida em que políticas sociais tenham sucesso".

O estudo de Gonçalves e França (2008), utilizando modelos multinível com a amostra dos SAEB 2003, constatou que existia uma correlação positiva entre a qualidade das escolas e a equidade dos resultados de alunos de diferentes níveis socioeconômicos. Para Gonçalves e França (2008, p. 655), “ as diferenças regionais em termos de renda e participação política são perpetuadas por seus sistemas educacionais".

Soares (2004) apontou alguns fatores externos que influenciam nas relações dos espaços escolares como a localização da escola, a violência associada ao local, tamanho da escola, que se relaciona ao número de alunos, o respeito às leis e ao regulamento estabelecido pelos sistemas de ensino, e seu grupo de alunos e professores e os recursos financeiros para equipá-la e pagar seus funcionários. Apoiando com os dados do SAEB 2001, Soares (2004) constatou que alguns fatores influenciavam no desempenho com a infraestrutura escolar e principalmente a condição socioeconômica dos alunos.

Mesmo após o rígido controle utilizado em relação às características dos alunos, observa-se clara evidência de que investimentos na infraestrutura escolar ainda produzem efeito nas escolas brasileiras. Ou seja, ainda não superamos a fase de investimento básico nas escolas. Ocorre aqui o mesmo fenômeno observado quanto aos fatores do professor em termos de equidade. Quando há melhoria nas condições da escola, a diferença de resultados entre grupos de alunos pelo sexo, cor da pele, nível socioeconômico e atraso escolar aumenta. Noutras palavras, os alunos mais favorecidos apropriam-se de forma mais eficiente da melhoria das condições da escola, aumentando assim as desigualdades. (SOARES, 2004. p. 98) 


\section{Metodologia e Resultados da pesquisa}

Para a realização das análises foi utilizada como fontes de dados a Prova Brasil de 2013 e 2015 disponibilizada pelo INEP. Nas análises por municipalidade não será apresentado o resultado do ensino privado, pois os microdados disponibilizados abrangem somente o ensino público do país. As médias das proficiências por municípios não são disponibilizados para o ensino médio; desta forma, a análise foi realizada somente para o ensino fundamental.

Klein (2006) fez uma interpretação de acordo com as habilidades necessárias para cada ano de escolaridade, definindo para o $5^{\circ}$ ano como nível básico 175, satisfatório 250 e avançado 300, para o $9^{\circ}$ ano, os níveis interpretáveis são somente o básico, 275, e o satisfatório, 350 em diante e para o ensino médio Nível básico: 375 e Nível satisfatório: 425, que servirão como base para as análises neste estudo.

A média nacional na proficiência de Matemática na Prova Brasil de 2015 foi de 222,23 para o $5^{\circ}$ ano do ensino fundamental; 257,73 para o $9^{\circ}$ ano do ensino fundamental e 267,6 para o ensino médio. Houve uma melhora em relação ao resultado alcançado em 2013, no qual foi de 211,21 para o $5^{\circ}$ ano do ensino fundamental, 249,63 para o $9^{\circ}$ do ensino fundamental e uma queda na média do ensino médio, que era 269,25.

A Tabela 1 mostra as médias de proficiência em Matemática por Grandes Regiões. Os resultados revelam que há diferenciações entre as regiões brasileiras, sugerindo ser resultantes de diferenças socioeconômicas e de políticas públicas na educação. Para o $5^{\circ}$ ano, todas as regiões brasileiras estariam no nível básico segundo a Interpretação de Klein (2006); já para o $9^{\circ}$ ano e para o ensino médio a situação se inverte, nenhuma se encaixaria no nível básico.

Tabela 1 - Média de proficiência em Matemática por Grandes Regiões, para $05^{\circ}$ e $9^{\circ}$ do ensino fundamental e ensino médio, 2013 e 2015

\begin{tabular}{l|c|c|c|c|c|c}
\hline \multirow{2}{*}{ Região } & \multicolumn{3}{|c|}{2013} & \multicolumn{2}{c}{2015} \\
\cline { 2 - 7 } & $5^{\mathbf{0}}$ ano & $9^{\mathbf{0}}$ ano & $\begin{array}{l}\text { Ensino } \\
\text { Médio }\end{array}$ & $5^{\mathbf{0}}$ ano & $9^{\mathbf{o}}$ ano & $\begin{array}{c}\text { Ensino } \\
\text { Médio }\end{array}$ \\
\hline Brasil & $\mathbf{2 1 1 , 2 1}$ & $\mathbf{2 4 9 , 6 3}$ & $\mathbf{2 6 9 , 2 5}$ & $\mathbf{2 2 2 , 2 3}$ & $\mathbf{2 5 7 , 7 3}$ & $\mathbf{2 6 7 , 6 0}$ \\
Centro-Oeste & 218,35 & 253,56 & 274,59 & 221,31 & 260,10 & 271,42 \\
Nordeste & 190,44 & 236,91 & 253,76 & 203,30 & 245,20 & 256,42 \\
Norte & 188,88 & 235,57 & 249,96 & 201,22 & 241,97 & 256,15 \\
Sudeste & 227,10 & 257,44 & 279,13 & 232,10 & 262,63 & 273,19 \\
Sul & 227,43 & 256,85 & 281,60 & 231,26 & 263,39 & 274,42 \\
\hline
\end{tabular}

Fonte: Prova Brasil 2013- 2015 (INEP/MEC).

O Gráfico 1 apresenta as médias em proficiência em Matemática no estado do Rio de Janeiro de acordo como a rede de ensino. O estado do Rio de Janeiro, na Prova Brasil de 2015, atingiu as médias de Proficiência em Matemática de 221,02 no $5^{\circ}$ ano do ensino fundamental, de 
260,45 no $9^{\circ}$ ano do ensino fundamental e de 273,97 no $3^{\circ}$ ano do ensino médio. Assim como ocorreu com a média nacional, a média dos $5^{\circ}$ e $9^{\circ}$ anos do ensino fundamental no estado melhoraram, que eram de 217,34 e 255,91, respectivamente. Já para o ensino médio, assim como a média do país, houve também uma queda no resultado em relação a edição de 2013, que correspondia a 282,98. Apesar de ter superado a média do país no 9 ano e no ensino médio na edição de 2015, os resultados ainda são insatisfatórios e ainda muito precisam ser melhorados.

Gráfico 1 - Média de Proficiência em Matemática, segundo a rede de ensino no estado do Rio de Janeiro, por ano de escolaridade 2013-2015

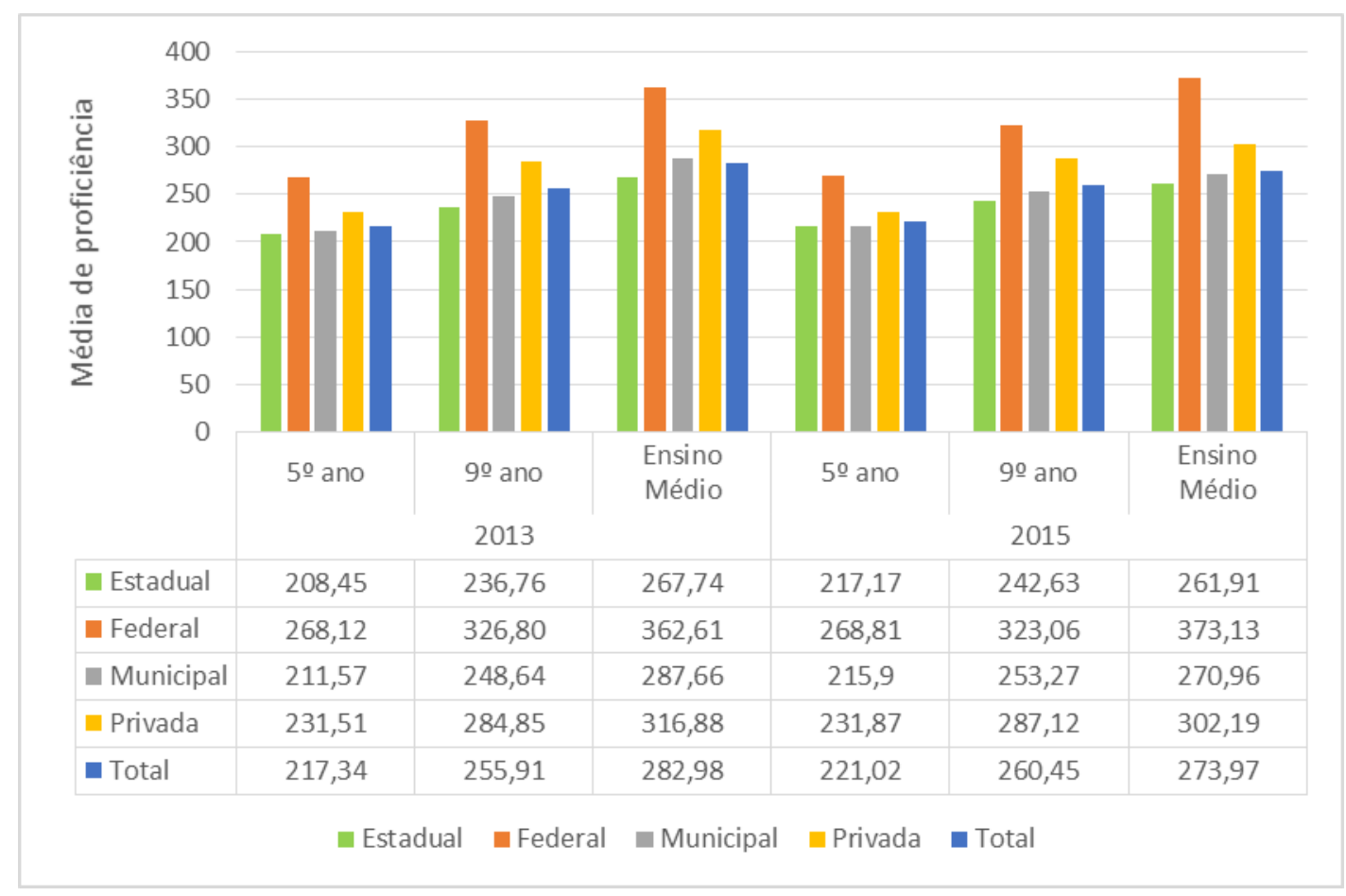

Fonte: Prova Brasil 2013- 2015 (INEP/MEC).

Nota - se ainda no Gráfico 1 que existe uma significativa superioridade entre a rede federal perante as outras em todos os resultados analisados. Segundo a interpretação de Klein (2006), para o $5^{\circ}$ ano, a rede federal atingiu o nível satisfatório e as demais conseguiram o nível básico. Ainda mediante esta interpretação, somente a rede federal e a rede privada obtiveram um ensino considerado básico para $9^{\circ}$ ano do ensino fundamental. Percebe- se que a rede estadual obteve uma média inferior a todas outras redes no ensino médio, na qual é proposto como prioridade no atendimento.

A Tabela 2 mostra o percentual de escolas analisadas por grupo econômico, revelando que a maioria das escolas estão nos grupos intermediários (médio e médio alto). Os resultados da edição da Prova Brasil de 2015 no estado do Rio de Janeiro constavam 3520 escolas, sendo de 24 da rede federal, 754 da rede estadual, 2619 da rede municipal e 123 da rede privada. Esta análise não pôde ser feita por dependência administrativa pelo fato de a maioria das escolas da rede privada não 
apresentar esse dado. Nota-se que nenhuma escola foi classificada no nível socioeconômico muito baixo no estado.

Tabela 2 - Distribuição percentual de escolas do ensino fundamental por grupo socioeconômico, estado do Rio de Janeiro, 2015

\begin{tabular}{c|c|c}
\hline Grupo & Frequência & Percentual \\
\hline Não classificado & 281 & 7,98 \\
\hline Muito baixo & 0 & 0,00 \\
\hline Baixo & 1 & 0,03 \\
\hline Médio Baixo & 23 & 0,65 \\
\hline Médio & 793 & 22,53 \\
\hline Médio Alto & 2141 & 60,82 \\
\hline Alto & 272 & 7,73 \\
\hline Muito Alto & 9 & 0,26 \\
\hline Total & 3520 & 100,00 \\
\hline
\end{tabular}

Fonte: Prova Brasil 2015- INEP/MEC.

A Tabela 3 mostra as respostas aos questionários da escola se ela apresenta depredação. Destaca-se que mais de $30 \%$ das escolas do estado do Rio responderam apresentar algum tipo de depredação, se havia vidros, portas e janelas quebradas, lâmpadas estouradas ou outros. Mais de 90 $\%$ das escolas responderam ter algum tipo de depredação, sendo 44, $1 \%$ apresentando muita.. Esse aspecto revela também a falta de conservação das escolas.

Tabela 3 - Resposta do Questionário se a escola apresenta algum tipo de depredação no estado do Rio de Janeiro , 2015

\begin{tabular}{c|c}
\hline Apresenta depredação &.$\%$ \\
\hline Não responderam & 5,9 \\
Sim, muita. & 44,1 \\
Sim, pouca. & 50,1 \\
Não. & 0 \\
\hline Total & 100 \\
\hline
\end{tabular}

Fonte: Prova Brasil 2015- INEP/MEC.

O Gráfico 2 apresenta as alcançadas no estado pelos 92 municípios agrupadas em intervalos. Observa-se pelo histograma que os dados não estão bem distribuídos de acordo com a média do estado, revelando as disparidades de resultados presentes. Analisando o gráfico percebe-se que alguns munícipios destacam-se por apresentarem uma média muito mais alta do que os demais ou mais baixa. 

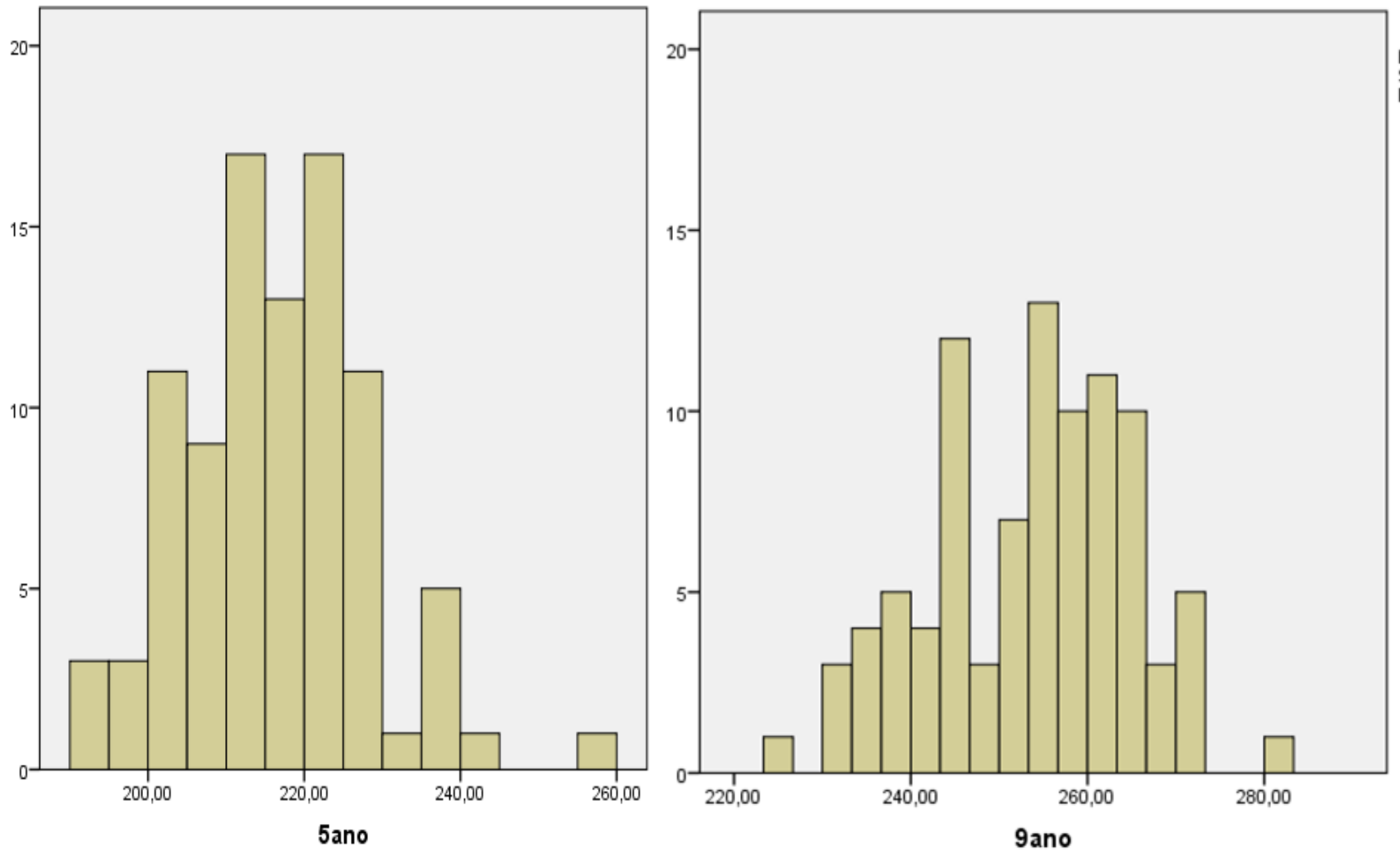

Fonte: Prova Brasil 2015- INEP/MEC.

A Tabela 4 apresenta os 10 primeiros municípios dentre os 92 municípios com as melhores médias na proficiência em Matemática no $5^{\circ}$ ano e no $9^{\circ}$ ano do ensino fundamental no estado. Nota-se que a maioria dos municípios com as maiores médias encontra-se no interior. Os municípios de Rio das Ostras e Comendador Levy Gasparian em 2015 foram os únicos que apareceram nos dois anos de escolaridade avaliados entre as 10 melhores médias do estado. Observa-se que não apresenta muita alteração na lista dos municípios 2015, comparando com a edição de 2013. Os resultados de 2013 e 2015 estão bem similares com os encontrados no trabalho de Souza (2014), que foi realizado com os dados de 2011.

Segundo a interpretação de Klein (2006), o município de Comendador Levy Gasparian seria o único do estado a ser considerado nível satisfatório para o $5^{\circ}$ ano do ensino fundamental e somente o município de Italva estaria no nível básico para o $9^{\circ}$ ano na edição da Prova Brasil de 2015. 
Tabela 4- Médias da Proficiência em Matemática dos 10 maiores resultados dos municípios no estado do Rio de Janeiro para o $5^{\circ}$ ano e $9^{\circ}$ ano do ensino fundamental, 2013-2015.

\begin{tabular}{|c|c|c|c|c|c|}
\hline \multicolumn{6}{|c|}{2015} \\
\hline \multicolumn{3}{|c|}{$5^{\circ}$ ano } & \multicolumn{3}{|c|}{$9^{\circ}$ ano } \\
\hline \multicolumn{2}{|c|}{ Município } & Média & \multicolumn{2}{|c|}{ Município } & Média \\
\hline 1. & Comendador Levy Gasparian & 258,14 & \multicolumn{2}{|c|}{ 1. Italva } & 280,54 \\
\hline 2. & Trajano de Moraes & 241,65 & \multicolumn{2}{|c|}{ 2. Santo Antônio de Pádua } & 272,64 \\
\hline 3. & Volta Redonda & 237,64 & \multicolumn{2}{|c|}{ 3. Sumidouro } & 272,59 \\
\hline 4. & Nova Friburgo & 237,61 & \multicolumn{2}{|c|}{ 4. Bom Jardim } & 272,46 \\
\hline 5. & Miguel Pereira & 237,47 & \multicolumn{2}{|c|}{ 5. Itaocara } & 271,88 \\
\hline 6. & Paty do Alferes & 236,95 & \multicolumn{2}{|c|}{ 6. Nova Friburgo } & 271,70 \\
\hline 7. & Rio das Ostras & 236,49 & \multicolumn{2}{|c|}{ 7. Rio das Ostras } & 267,84 \\
\hline 8. & Miracema & 234,07 & \multicolumn{2}{|c|}{ 8. Quatis } & 267,42 \\
\hline 9. & Itatiaia & 229,65 & \multicolumn{2}{|c|}{ 9. Comendador Levy Gasparian } & 266,73 \\
\hline 10. & Bom Jardim & 229,05 & \multicolumn{2}{|c|}{ 10. Cambuci } & 265,64 \\
\hline \multicolumn{6}{|c|}{2013} \\
\hline \multicolumn{3}{|c|}{$5^{\circ}$ ano } & \multicolumn{3}{|c|}{$9^{\circ}$ ano } \\
\hline \multicolumn{2}{|c|}{ Município } & Média & \multicolumn{2}{|c|}{ Município } & Média \\
\hline 1. & Comendador Levy Gasparian & 249,59 & & Itaocara & 279,50 \\
\hline 2. & Sumidouro & 244,95 & 2. & Italva & 274,49 \\
\hline 3. & Miguel Pereira & 242,01 & 3. & Cantagalo & 273,12 \\
\hline 4. & Paty do Alferes & 239,66 & 4. & Bom Jardim & 272,71 \\
\hline 5. & Nova Friburgo & 235,95 & 5. & 5. Cambuci & 272,66 \\
\hline 6. & Bom Jardim & 235,92 & 6. & Nova Friburgo & 271,72 \\
\hline 7. & Itaocara & 235,74 & 7. & Duas Barras & 270,54 \\
\hline 8. & Mendes & 235,67 & 8. & Miguel Pereira & 269,47 \\
\hline 9. & São Sebastiao do Alto & 233,97 & 9. & São Sebastiao do Alto & 269,23 \\
\hline 10. & São Jose de Ubá & 233,71 & 10. & Pirai & 268,61 \\
\hline
\end{tabular}

Fonte: Prova Brasil 2013-2015 (INEP/MEC).

As menores médias do estado em 2015 para o $5^{\circ}$ ano do ensino fundamental foram do município de Japeri com a média de 191,6, Nilópolis de 192,65 e Queimados de 193,76. Para o 9 ano, a menor média foi também para Japeri de 225,68 seguida de Belford Roxo 231,74 e Queimados 231,97, municípios da região da Baixada Fluminense do estado.

Em 2013 as menores médias da proficiência em Matemática do $5^{\circ}$ ano do ensino fundamental ficaram com os municípios de Queimados, sendo a média de 180,54, Macuco de 180,59 e Belford Roxo de 185,66. Já para o $9^{\circ}$ ano, o município de São Jose de Ubá apresentou o menor resultado, sendo de 215,61, depois Japeri de 219,31 e Queimados de 222,57.

Analisando os dados de todos os municípios do estado, verifica-se que dentre os 20 municípios com as médias mais baixas, a maioria pertence à região metropolitana do estado, tanto para o $5^{\circ}$ ano quanto para o $9^{\circ}$ ano do ensino fundamental. Cabe ressaltar que não apareceu qualquer município do estado com Rio de Janeiro entre os primeiros colocados do país nas edições 
de 2013 e 2015. No trabalho de Souza (2014) foi identificado que somente $35,87 \%$ dos municípios do estado do Rio de Janeiro estavam acima da média estadual em Matemática, que era de 259,71 em 2011.

\section{Considerações Finais}

No estudo pode-se observar que os resultados na proficiência em Matemática ainda são considerados insatisfatórios, principalmente no $9^{\circ}$ ano do ensino fundamental e no ensino médio. Boa parte dos municípios não atingiram sequer o nível básico de acordo com as habilidades necessárias para os anos de escolaridades avaliados.

Notam-se as desigualdades regionais até mesmo de municípios próximos geograficamente, mas com resultados bem distintos. Ainda podemos perceber que alguns municípios considerados mais ricos obtiveram um índice não muito satisfatório, não aparecendo entre os dez primeiros em nenhum dos anos pesquisados. Deixa-nos refletir se os investimentos em educação no município estão sendo adequados ou abaixo do necessário.

Não podemos olhar os dados isoladamente e sabemos que existem alguns fatores que influenciam no desempenho escolar que não podemos mensurar, mas que são de importância no processo de ensino-aprendizagem. Neste trabalho foi destacado o nível socioeconômico da escola e a presença de depredação, mas haveriam outras variáveis que poderiam influenciar no resultado, porém caberia um estudo mais detalhado.

Apesar de existirem muitas críticas sobre a Prova Brasil, que vão desde as formulações das questões, a forma de aplicação das provas e questionários, análise somente da escola sem outras interferências externas (sociais e políticas), a não obrigação de estudantes do ensino médio, ou ainda que algumas escolas fazem preparatório para esta prova, as avaliações fazem parte do sistema de ensino brasileiro e servem como um referencial para a pesquisa em educação.

Observou-se no trabalho que há uma variação entre as diferentes municipalidades do Rio de Janeiro e que as médias ainda demonstram o baixo desempenho na disciplina.

\section{Referências}

ALVES, M. T. G.; SOARES, J. F. Contexto escolar e indicadores educacionais: condições desiguais para a efetivação de uma política de avaliação educacional. Educ. Pesquisa [online]. 2013, vol.39, n.1, pp.177-194. Disponível em:〈 http://www.scielo.br/pdf/ep/v39n1/v39n1a12.pdf> Acesso em: 12 fev. 2016.

BARROS, R. P. et al. Determinantes do desempenho educacional do Brasil. Pesquisa e

Planejamento Econômico, Rio de Janeiro, v.31, n.1. p.1-42, abr. 2001. 
BRASIL. Ministério da Educação e do Desporto/INEP. Índice de Desenvolvimento da Escola Pública. Disponível em <http://ideb.inep.gov.br>. Acesso em 20 ago. 2016.

BECKER, F. da R.. Avaliação educacional em larga escala: a experiência brasileira. Avaliação educacional em larga escala. Revista Iberoamericana de Educación, n. 53. p.1 -11, 2010.

INSTITUTO NACIONAL DE ESTUDOS E PESQUISAS EDUCACIONAIS ANÍSIO TEIXEIRAINEP. Escalas de Proficiências da Prova Brasil. Disponível

em:<http://download.inep.gov.br/educacao_basica/prova_brasil_saeb/escala/escala_proficiencia/20 13/escala_ensino_medio_2013.pdf > Acesso em fev. 2016 a.

. SAEB. Disponível em: <www.inep.gov.br>. Acesso em: 2 abr. $2016 b$.

. Microdados da Aneb e da Anresc 2015. Brasília: Inep, 2015. Disponível em:

<http://portal.inep.gov.br/basica-levantamentos-acessar>. Acesso em: 30 jan. 2017.

. Microdados da Aneb e da Anresc 2013. Brasília: Inep, 2017. Disponível em:

<http://portal.inep.gov.br/basica-levantamentos-acessar>. Acesso em: 10 fev. 2016.

GONÇALVES, F. O.; FRANÇA, M. T. A.. Transmissão intergeracional de desigualdade e qualidade educacional: avaliando o sistema educacional brasileiro a partir do SAEB 2003. Ensaio: Avaliação e Políticas Públicas em Educação, v. 16, n. 61, p. 639-662, 2008.

KLEIN, R.. Como está a educação no Brasil? O que fazer? Ensaio: Avaliação e Políticas Públicas em Educação. Rio de Janeiro, RJ, v. 14, n. 51, abr. - jun. 2006. p. 139 - 172.

MENEZES FILHO, N. A.. Os determinantes do desempenho escolar do Brasil Instituto Futuro Brasil, Ibmec-SP e FEA-USP, 2007. Disponível em: <

http://www.todospelaeducacao.org.br//arquivos/biblioteca/f4e8070a-8390-479c-a532803bbf14993a.pdf > .. Acesso em: 10 ago 2013.

SOARES, J. F. O Efeito da Escola no Desempenho Cognitivo de seus Alunos. Revista Electrónica Iberoamericana sobre Calidad, Eficacia y Cambio en Educación (REICE), v. 2, n. 02, 2004. Disponível em: <http://www.ice.deusto.es/RINACE/reice/vol2n2/Soares.pdf>. Acesso em: 5 jun. 2015.

SOUZA, E. Uma análise dos resultados da proficiência em matemática na Prova Brasil no estado do Rio de Janeiro. In: ENCONTRO ESTADUAL DE EDUCAÇÃO MATEMÁTICA, 2014, 6, Niterói, RJ. Anais... Niterói: SBEM- RJ, 2014. Disponível em:< http://www.sbemrj.com.br/p/anais.html >. Acesso em: 12 set. 2016.

UNICEF, PNUD, INEP-MEC (coordenadores). Indicadores da qualidade na educação / Ação Educativa, - São Paulo: Ação Educativa, 2004.

VALLE SILVA, N.; BARBOSA, M. L. de O. Desempenho individual e organização escolar na realização educacional. Sociologia \& Antropologia, v. 2, n. 4, p. 159, 2012.

Submetido em janeiro de 2017 Aprovado em março de 2017 